Iustitia Socialis. Revista Arbitrada de Ciencias Jurídicas.

Año IV. Vol. IV. Nº 1. Edición Especial 2019

Hecho el depósito de Ley: FA2016000064 ISSN: 2542-3371

FUNDACIÓN KOINONIA (F.K). Santa Ana de Coro, Venezuela

Tania Gabriela Villacreces Briones, Jorge Luis Villacreces Palomeque

http://dx.doi.org/10.35381/racji.v4i1.535

\title{
La constitucionalización del principio de proporcionalidad en España y la actividad legislativa penal
}

\section{The constitutionalization of the principle of proportionality in Spain and criminal legislative activity}

\author{
Tania Gabriela Villacreses Briones \\ tgvillacreses@sangregorio.edu.ec \\ Universidad San Gregorio de Portoviejo, Manabí \\ Ecuador. \\ https://orcid.org/0000-0002-0152-4506 \\ Jorge Luis Villacreses Palomeque \\ ¡lvillacreses@sangregorio.edu.ec \\ Universidad San Gregorio de Portoviejo, Manabí \\ Ecuador \\ https://orcid.org/0000-0002-7566-8190
}

Recibido: 30 de octubre de 2019

Aprobado: 02 de diciembre de 2019

\section{RESUMEN}

La posición del Tribunal Constitucional español frente a la actividad legislativa penal, ha sido desarrollada a través de su jurisprudencia; en esta investigación se ha tomado para análisis al principio de proporcionalidad como límite de creación de la ley penal, según la jurisprudencia constitucional española. Consideramos que dentro de esta sentencia el Tribunal Constitucional además de abordar los problemas que se le plantean, asienta precedente acerca de la amplia libertad que tiene el Parlamento español a la hora de determinar los delitos y las penas del Código Penal, y el respecto a su labor discrecional, tan distinto al caso ecuatoriano, donde la labor parlamentaria debe adecuarse y desarrollarse en razón de los derechos y principios consagrados en la Constitución y los Tratados Internacionales de Derechos Humanos, con funciones casi absolutamente detalladas y limitadas.

Descriptores: Proporcionalidad; tribunal constitucional; constitucionalismo; pautas; límites. 


\begin{abstract}
The position of the Spanish Constitutional Court regarding criminal legislative activity has been developed through its jurisprudence; In this investigation, the principle of proportionality was taken as an analysis to limit the creation of the criminal law, according to Spanish constitutional jurisprudence. We consider that, within this judgment, the Constitutional Court, in addition to addressing the problems that arise, sets a precedent about the broad freedom that the Spanish Parliament has in determining the crimes and penalties of the Criminal Code, and the respect for their Discretionary work, so different from the Ecuadorian case, where parliamentary work must be adapted and developed based on the rights and principles enshrined in the Constitution and International Treaties on Human Rights, with functions almost absolutely detailed and limited.
\end{abstract}

Descriptors: Proportionality; constitutional court; constitutionalism; guidelines; limits.

\title{
INTRODUCCIÓN
}

Las actuales dificultades a las que se enfrenta el panorama jurídico ecuatoriano en relación a la falta de estándares fijos que guíen la actividad del poder legislativo, no en su ámbito sistemático procedimental, sino dentro de la fase sustantiva de producción de normas; invita a aproximarnos al análisis de sistemas jurídicos externos en cuanto a la producción racional del derecho de parte de los Tribunales Constitucionales, respecto a la elaboración de pautas de creación normativa, dentro del mayor reto que tiene este alto órgano constitucional y el constitucionalismo contemporáneo en sí mismo, y es la acepción del tribunal constitucional como limitador legislativo y legislador negativo.

\section{MÉTODO}

La investigación tiene por objetivo analizar la constitucionalización del principio de proporcionalidad en España y la actividad legislativa penal, partiendo de una revisión documental - jurídica sobre el tema, lo que permitió realizar un análisis sobre las diversas aristas que conforman la variable de estudio, utilizando procesos de interpretación, inferencia, que contribuyeron al logro del propósito planteado, empleándose la técnica de análisis de contenido para escrutar la información seleccionada, siguiendo lo propuesto por Hernández, Fernández \& Batista (2014), en relación de la construcción metodológica de la investigación documental. 


\section{RESULTADOS}

A lectura simple, la Constitución española de 1978 no contempla de forma expresa el principio de proporcionalidad, y siendo precisos, la palabra "proporcional" en su dimensión jurídica de equilibrio y límite al poder del Estado, como básica acepción, no se encuentra contenida de forma explícita de ningún modo; sin embargo, existe consenso general en considerar que el principio se halla consagrado implícitamente en otros principios constitucionales y por ende revestido de carácter constitucional.

En el seno de la doctrina española suele considerarse que, bajo la expresión de principios constitucionales en materia penal se "estudian los tradicionalmente denominados límites al ius puniendi, considerando que desde el momento en que las Constituciones en su parte dogmática consagran los derechos y libertades fundamentales, implícita o explícitamente contemplan a la vez los límites del poder punitivo y los principios fundamentales informadores del Derecho penal"1 como lo es el principio de proporcionalidad.

Está claro que, de las constituciones se derivan los principios y reglas que rigen el proceso penal, la imputación de las conductas y el fin de la pena ${ }^{2}$ lo que ha hecho que lo denominen como Derecho penal constitucional. Los principios consagrados por la Constitución con relevancia penal serían los valores superiores de libertad, igualdad, pluralismo y justicia, determinados en el artículo 1 de la Constitución española, de estos se derivarían los principios de racionalidad y proporcionalidad de forma implícita.

La concepción del Estado de Derecho, connota que los principios consagrados constitucionalmente "no son mandatos rígidos o estancados, sino que al contrario, cada uno de ellos cobra valor en función de los demás, en tanto sirvan para promover los valores y derechos del ordenamiento jurídico que propugna el Estado social y democrático de Derecho"3 enmarcándose así en el ideal de justicia.

\footnotetext{
${ }^{1}$ Cobo del Rosal, Manuel 1999, en Aguado Correa, Teresa, "El principio de proporcionalidad y el derecho penal", Madrid, EDER.SA.

2 Arroyo Zapatero, Luis 1997, "Derecho Penal Económico Y Constitución”, Madrid, Revista RP, Volumen 1, $\mathrm{N}^{\circ} 13$, pág. 13.

${ }^{3}$ STC 27/1981, f j. 10 .
} 
No obstante, a lo anterior mencionado, no existe acuerdo de parte de los estudiosos del tema, ni consenso general en la academia para el caso español, en la determinación del artículo de la Constitución española en el que este principio se ubique implícitamente, siendo así que, son varios los autores que realizan sus propias interpretaciones a los preceptos constitucionales, localizando al principio de proporcionalidad en diferentes artículos.

Teresa Aguado, en su obra sobre el principio de proporcionalidad y el Derecho penal, cita:

Gimeno Sendra considera que el principio de proporcionalidad se encuentra implícitamente contenido en el artículo 25 de la Constitución española, que al consagrar el principio de legalidad no establece exclusivamente el de tipicidad, sino también el de proporcionalidad, y más concretamente se encuentra implícitamente contenido en todos aquellos preceptos en los que se establecen los límites del ejercicio de los derechos fundamentales (artículos. 20.4, 21.2, 22.2 y 22.5 de la CE) y los artículos 5.1, 8.2, 10.2, 11.2 y 15 del CEDH.

En opinión de González-Cuéllar, el principio de proporcionalidad se podría inferir principalmente del artículo 53.1 de la Constitución, sin olvidar los artículos $1.1,9.3$ y 10.1 de la misma.

La misma autora considera que:

El principio de proporcionalidad tendría rango constitucional, pues deriva, según este autor, de la fuerza normativa de los derechos fundamentales, por lo que es en el artículo 53.1 donde encontraría sustento en el proceso penal, a pesar de que no se incluya en el tenor literal de este precepto ni al Poder Judicial ni al Ejecutivo, ya que en el propio artículo constitucional 53.1 se habilita al poder Legislativo para definir las posibilidades de actuación de aquéllos sobre los derechos y libertades reconocidos en el capítulo segundo del Título I de la Constitución española ${ }^{4}$.

Esta "libertad de actuación" que la misma Constitución española otorga a los legisladores, es la que debe estar orientada por pautas de proporcionalidad, que, en el caso español, son desarrolladas por vía de jurisprudencia, en ampliación de los

\footnotetext{
${ }^{4}$ Aguado Correa, Teresa 1999, "El principio de proporcionalidad y el Derecho penal" Madrid, EDER.SA.
} 
preceptos constitucionales que las fundamentan. Otros autores, como López Garrido y García Aran, sostienen que:

El principio de proporcionalidad es un principio tan consustancial al sistema sancionatorio que puede considerarse implícito en el mismo, de modo que cuando la Constitución acoge en su texto el concepto de pena puede entenderse que de esta manera recibe todas las características consustanciales a este concepto, entre las que se encuentra la proporcionalidad entre la gravedad objetiva y subjetiva del hecho ${ }^{5}$.

Para estos dos autores, de esta forma, el principio de proporcionalidad estaría implícito en el Derecho constitucional español. Ante lo mencionado en cita, el Tribunal Constitucional español como máximo órgano garante e intérprete de la Constitución, y en razón de la dinámica jurídica constitucional española, ha sido el órgano que se ha pronunciado sobre la formulación, concepción, contenido y consagración constitucional del principio de proporcionalidad en algunas sentencias.

Tenemos así por ejemplo: la STC 66/1995 FJ6 que manifiesta que el principio de proporcionalidad es aquel que: "exige una relación ponderada de los medios empleados con el fin perseguido para evitar el sacrificio innecesario o excesivo de los derechos fundamentales", la STC111/1993 FJ 9, STC 55/1996 FJ 3, la STC 59/2008 que será razón de análisis en el siguiente capítulo de la investigación, la STC 55/1996, STC 136/199 o la STC 85/1994 conocida como la sentencia del hachís ${ }^{6}$, entre otras.

Estas sentencias plantean las discusiones que pueden presentar ciertas figuras jurídicas, desde una amplia dimensión y visión constitucional en relación con el principio de proporcionalidad. En alusión al enfoque que se pretendió en la investigación dentro de la línea de una "democracia constitucional" y la consolidación de esta como el modelo de Estado en España, la Constitución en el artículo 1 proclama un Estado social y democrático de derecho, lo que se vuelve un fundamento más, constitucional, para la consideración de cualquier principio implícito relativo a los límites del ius puniendi como lo es el estudio del principio de proporcionalidad.

5 López Garrido, Diego, García Aran, Mercedes 1995, "El Código Penal de 1995 y la voluntad del legislador, comentario al texto y al debate parlamentario", Madrid, Trota.

${ }^{6}$ Aguado Correa, Teresa, op. cit, 1999, pág. 81. 
De este último modo, se ha manifestado el Tribunal Constitucional español determinando que: "al efectuar un juicio de proporcionalidad debe tenerse también muy presente la relevancia que en el mismo tiene el criterio de la proporcionalidad como principio inherente del Estado de Derecho y la democracia constitucional"7

A la vez, el Tribunal Constitucional español ha "incorporado y hecho suya la jurisprudencia de los Tribunales Supranacionales Europeos y, en relación con el principio de proporcionalidad, ha adoptado como propio el llamado test alemán"8. Hoy es ya doctrina general considerar que al control del principio de proporcionalidad lo conforma el estudio de la adecuación o idoneidad de la medida legislativa objeto de examen, una revisión de la necesidad de la misma y un control de proporcionalidad en sentido estricto, atendiendo sus consecuencias ${ }^{9}$.

Complementario a lo antes indicado, con respecto específicamente a la actividad legislativa y el principio de proporcionalidad, el Tribunal Constitucional español considera que la creación de una norma desproporcionada "socava los principios elementales de justicia inherentes a la dignidad de la persona y al Estado de Derecho $^{10 "}$ y determina que para que una medida legislativa sea considerada como proporcional, debe cumplir el juicio de idoneidad y de necesidad.

Sobre esto, el Tribunal Constitucional español, ha determinado que una medida legal solo será proporcional si: "La misma es ponderada o equilibrada, por derivarse de ella más beneficios o ventajas para el interés general que perjuicios sobre otros bienes o valores en conflicto ${ }^{11}$ " refiriéndose así, al juicio de proporcionalidad en sentido estricto".

Sin embargo y dentro de los párrafos formulados, Medina Guerrero para el caso español, nos recuerda que la posición constitucional del legislador a la que hemos aludido, obliga al legislador español a que la aplicación del principio de proporcionalidad como canon de control constitucional de sus decisiones, deba tener

\footnotetext{
${ }^{7}$ STC 85/1992, f j. 4.

8 Soto García, Ángel 2002 "El principio de proporcionalidad como criterio para determinar la constitucionalidad de las intervenciones en derechos fundamentales", Revista de la Red Iberoamericana de estudios de derecho constitucional, Volumen $1, \mathrm{~N}^{\circ} 66$, pág. 12.

${ }^{9}$ STC 55/1996 f. j. 5.

${ }^{10}$ STC 55/1996, f. j. 7

${ }^{11}$ STC 55/1996, f. j. 8
} 
lugar de forma y con intensidad cualitativamente distinta a las aplicadas a los órganos encargados de aplicar e interpretar las leyes ${ }^{12}$, de acuerdo a la STC $11 / 1981$.

En España su Tribunal Constitucional ha reiterado que el legislador español no se limita a ejecutar o aplicar la Constitución, sino que, dentro del marco que ésta traza, adopta libremente las opciones políticas que en cada momento estima más oportunas $^{13}$.

Esto último lo podemos observar al analizar las sentencias del Tribunal Constitucional español antes mencionadas, casi todas desestimatorias, considerando al principio de proporcionalidad en España como un límite implícito a la actividad parlamentaria pero solo en casos muy señalados, siempre que la desproporción sea muy evidente y palpable. Teniendo como primer resultado, el respeto a las opciones del legislador, que el Tribunal Constitucional español considera debe existir, dentro de las que caben distintas opciones de política legislativa.

La Constitución española permite distintas líneas políticas, y en base a esta premisa, asiente en que la creación y reforma de leyes no se sujeta al desarrollo y ejecución de la Constitución; otorgando al legislador español un amplio margen de discrecionalidad en su actuar.

El razonamiento de parte del Tribunal Constitucional español, respecto a la actividad parlamentaria de sus legisladores ante los conflictos de control constitucional de proporcionalidad de las normas penales, ha sido uniforme, teniendo como única excepción la STC 136/1999.

En esta última sentencia en mención, se cuestiona la proporcionalidad de la pena impuesta a los miembros de la Mesa Nacional de Herri Batasuna por el delito de colaboración con banda armada, previsto en el artículo 174 del Código Penal español de 1973, que establecía una pena de prisión mayor de: seis años y un día a doce años.

\footnotetext{
${ }^{12}$ Medina Guerrero, Manuel, op. cit, 1998, pág. 12.

${ }^{13}$ Medina Guerrero, Manuel, op. cit, 1998, pág. 13.
} 
El Tribunal Constitucional español realiza el estudio de proporcionalidad en todas sus dimensiones, y es en el análisis de su último eslabón relativo al estudio de "proporcionalidad en sentido estricto", que por primera vez, estima que existe desproporción de una pena, considerando que esta: "no guarda, por su excesiva severidad, y en relación a los efectos que la misma comporta para el ejercicio de las libertades de expresión y de información, una razonable relación con el desavalor que entrañan las conductas sancionadas".

El Tribunal Constitucional español estima que la norma penal no distingue la gravedad de los distintos comportamientos posibles de colaboración con una banda armada, asignando la misma pena a todos ellos.

Para esta declaración de desproporción de una norma penal, el Tribunal Constitucional, usó de argumento principal, la incidencia de la conducta sancionada en el ejercicio legítimo de las libertades de expresión y de participación política, y la escasa lesividad del comportamiento perseguido penalmente, resultando: "alejadas de los peligros que la norma aplicada quiere finalmente evitar".

El Tribunal Constitucional considera que la respuesta penal es desproporcionada, frente a las eventuales extralimitaciones en el ejercicio de libertades, lo que puede disuadir el ejercicio legítimo de estas por los ciudadanos.

En el plano supranacional europeo, el principio de proporcionalidad se encuentra también reconocido por la jurisprudencia del Tribunal de Justicia de la Unión Europea ${ }^{14}$.

Ésta ha venido desarrollando el principio de proporcionalidad desde el año 1970 en la revisión de las normas y resoluciones administrativas que le han sido sometidas a su consideración, hasta el punto de calificarlo como "el principio más importante en el ámbito del Derecho del Mercado Común ${ }^{15 " .}$

Acotaciones respecto al sistema español, relativas a la validez constitucional del delito de negativa a someterse a pruebas de comprobación de conducción bajo influencia de alcohol, drogas tóxicas y estupefacientes, y el principio de

\footnotetext{
14 Barnes, Javier 2009, "Introducción al principio de proporcionalidad en el Derecho comparado y comunitario", Revista de Administración Pública, Volumen 1, $\mathrm{N}^{\circ} 135$.

15 Barnes, Javier, op. cit, 2009, pág. 14.
} 
proporcionalidad, de acuerdo a la Sentencia del Tribunal Constitucional español 61/1996.

La Sentencia aborda el problema de la validez constitucional del delito de negativa a someterse a pruebas de alcoholemia, en cuanto a los trascendentales bienes jurídicos que juegan parte de sus consecuencias. Se plantea una cuestión de inconstitucionalidad en relación con el artículo 380 del Código Penal español, Ley Orgánica 10/1995 del 23 de noviembre de 1995, tipificado como "desobediencia grave de la negativa del conductor a someterse a la prueba de alcoholemia".

El órgano que plantea la cuestión estima en primer término que el delito puede contrariar los derechos del detenido a no declarar contra sí mismo y no confesarse culpable, consagrados constitucionalmente como derechos fundamentales, por la consecuencia jurídica que se deriva de la negativa a someterse a pruebas legalmente establecidas. El órgano promotor conecta la litis con el principio de proporcionalidad de las penas; en su opinión el legislador podría haberse excedido en su competencia en el ámbito de su política criminal y vulnerar los ya mencionados derechos fundamentales.

La razón que argumenta para sustentar lo anterior es la de que la pena imponible por el ya mencionado delito tipificado en el artículo 380 del Código Penal es la de prisión de seis meses a un año mientras que la prevista para el delito que trata de comprobarse, es la de arresto de ocho a doce fines de semana o multa de tres a ocho meses, es decir la penalidad para el delito "principal" es de menor gravedad que la establecida para el delito cuestionado, sin que exista justificación alguna para ello. El fondo de la cuestión suscita dos problemas principales, primero la conformidad del artículo en cuestión con los derechos a no declarar contra sí mismo y a no confesarse culpable, y en segundo lugar, la proporcionalidad de la pena.

Respecto al primero el Tribunal Constitucional considera que las pruebas de detección consisten en la espiración de aire, en la extracción de sangre, en análisis de orina $o$ en un examen médico; y que estas no constituyen actuaciones encaminadas a obtener del sujeto el reconocimiento de determinados hechos o su interpretación o valoración de los mismos, sino simples pericias de resultado incierto. 
El Tribunal Constitucional en relación al segundo punto en cuestión, considera que la configuración del delito genérico de desobediencia grave parte de una interpretación no irrazonable pero discutible; determinan que es propio del delito de desobediencia el ánimo del sujeto activo de socavar, desprestigiar o menospreciar el principio de autoridad, y que deben estudiarse las consecuencias de estas conductas pero que no corresponde al Tribunal Constitucional sino a los órganos judiciales y al Tribunal Supremo, indicar cómo han de interpretarse los preceptos penales.

El Tribunal Constitucional estima que no se puede calificar en absoluto de irrazonable el que el legislador haya decidido catalogar como grave un determinado tipo de desobediencia en virtud de que se produce en un ámbito socialmente tan trascendente como es el de la seguridad del tráfico en relación con la conducción bajo la influencia de las drogas o del alcohol.

La orden cuya desobediencia se sanciona tiende a proteger, en última instancia, bienes tan trascendentales como la vida y la integridad física de las personas. Por lo acotado, el Tribunal Constitucional español desestima la acción de inconstitucionalidad.

Consideramos que dentro de esta sentencia el Tribunal Constitucional además de abordar los problemas que se le plantean, asienta precedente acerca de la amplia libertad que tiene el Parlamento español a la hora de determinar los delitos y las penas del Código Penal, y el respecto a su labor discrecional, tan distinto al caso ecuatoriano, donde la labor parlamentaria debe adecuarse y desarrollarse en razón de los derechos y principios consagrados en la Constitución y los Tratados Internacionales de Derechos Humanos, con funciones casi absolutamente detalladas y limitadas. 


\section{REFERENCIAS CONSULTADAS}

1. Arroyo Zapatero, L. (1997). Derecho Penal Económico y Constitución. Madrid, Revista RP, Volumen 1, №13, pág. 13.

2. Aguado Correa, T. (1999). El principio de proporcionalidad y el Derecho penal. Madrid, EDER.SA.

3. Barnes, J. (2009). Introducción al principio de proporcionalidad en el Derecho comparado y comunitario. Revista de Administración Pública, Volumen 1, No135.

4. Cobo del Rosal, M. (1999), en Aguado Correa, Teresa, "El principio de proporcionalidad y el derecho penal", Madrid, EDER.SA.

5. Hernández, R., Fernández, C., Baptista, P. (2014). Metodología de la Investigación. México: Editorial Mc - Graw - Hill Interamericana.

6. López Garrido, D, García Aran, M. (1995). El Código Penal de 1995 y la voluntad del legislador, comentario al texto y al debate parlamentario. Madrid, Trota.

7. Soto García, A. (2002). El principio de proporcionalidad como criterio para determinar la constitucionalidad de las intervenciones en derechos fundamentales, Revista de la Red Iberoamericana de estudios de derecho constitucional, Volumen 1, №66, pág. 12.

8. Sentencia 55/1996, de 28 de marzo. Recuperado de http://hj.tribunalconstitucional.es/es-ES/Resolucion/Show/3107

9. Sentencia 27/1981, de 20 de julio. Recuperado de https://hj.tribunalconstitucional.es/de-DE/Resolucion/Show/27

10. Sentencia 85/1992, de 8 de junio. Recuperado de http://hj.tribunalconstitucional.es/es-ES/Resolucion/Show/1972

\section{REFERENCES CONSULTED}

1. Arroyo Zapatero, L. (1997). Economic Criminal Law and Constitution. Madrid, RP Magazine, Volume 1, No. 13, p. 13.

2. Aguado Correa, T. (1999). The principle of proportionality and criminal law. Madrid, EDER.SA. 
3. Barnes, J. (2009). Introduction to the principle of proportionality in comparative and community law. Public Administration Magazine, Volume 1, No. 135.

4. Cobo del Rosal, M. (1999), in Aguado Correa, Teresa, "The principle of proportionality and criminal law", Madrid, EDER.SA.

5. Hernández, R., Fernández, C., Baptista, P. (2014). Investigation methodology. Mexico: Editorial Mc - Graw - Interamerican Hill.

6. López Garrido, D, García Aran, M. (1995). The Criminal Code of 1995 and the will of the legislator, comment on the text and the parliamentary debate. Madrid, jogs.

7. Soto García, A. (2002). The principle of proportionality as a criterion for determining the constitutionality of interventions in fundamental rights, Journal of the Ibero-American Network of Constitutional Law Studies, Volume 1, No. 66, p. 12.

8. Judgment 55/1996, of March 28. Recovered from http://hj.tribunconstitucional.es/es-ES/Resolucion/Show/3107

9. Judgment 27/1981, of July 20 . Recovered from https://hj.tribunconstitucional.es/de-DE/Resolucion/Show/27

10. Judgment 85/1992, of June 8. Recovered from http://hj.tribunconstitucional.es/es-ES/Resolucion/Show/1972 